\title{
Radial Immunodiffusion Test with a Brucella Polysaccharide Antigen for Differentiating Infected from Vaccinated Cattle
}

\author{
RAMON DIAZ,' PEDRO GARATEA, ${ }^{1}$ LOIS M. JONES, ${ }^{2 *}$ AND IGNACIO MORIYON ${ }^{2}$ \\ Faculty of Medicine, University of Navarra, Pamplona, Spain, ${ }^{1}$ and Department of Veterinary Science, \\ University of Wisconsin-Madison, Madison, Wisconsin $53706^{2}$
}

Received for publication 6 April 1979

\begin{abstract}
A Brucella antigen containing polysaccharide but lacking smooth lipopolysaccharide was employed in a rapid radial immunodiffusion test. With this serological test, cattle infected with Brucella abortus could be identified in recently vaccinated herds which had high numbers of reactors to standard diagnostic tests.
\end{abstract}

It was shown by immunoelectrophoresis that trichloroacetic acid, phenol-water, and etherwater extracts of smooth strains of Brucella abortus and Brucella melitensis contain two major components of cathodic mobility (4).

One component has been identified as a lipopolysaccharide-protein complex (S-LPS) with endotoxic activity (8) which carries the specificity for smooth surface agglutinogens of Brucella species (4). The S-LPS complex was also shown to be the major antigenic component involved in serological tests routinely used for the diagnosis of brucellosis $(4,5)$.

The other component has been distinguished by greater diffusibility in immunoelectrophoresis and immunodiffusion tests (4), lack of endotoxic activity, and higher carbohydrate content (3) and was designated polysaccharide B (poly B) (5). This component apparently plays no role in agglutination tests since antibodies to poly B present in sera from infected animals can be removed by absorption with poly $B$ without affecting the agglutinin titers of the sera $(4,5)$.

Sera from cattle infected with $B$. abortus generally have antibodies to S-LPS, but sera from cattle vaccinated with smooth living cells of $B$. abortus attenuated strain 19 may also contain antibodies to S-LPS for varying periods after vaccination. These latter sera present a problem in the interpretation of diagnostic tests (12).

In preliminary studies, antibodies to poly $B$ were not observed in sera of vaccinated cattle, although they had been demonstrated in sera from infected cattle (5) and persons with clinical brucellosis (6). It was thought, therefore, that the use of an antigen containing poly $B$ but lacking S-LPS might help identify infected cattle in recently vaccinated populations.

It had been shown previously that a trichloroacetic acid extract of $B$. melitensis rough strain B115 lacked S-LPS but contained poly B (4). The radial immunodiffusion (RID) test has been employed with bovine sera and soluble brucella antigens (7). In the present study, the RID test with poly B prepared from strain B115 incorporated into the gel was used to examine sera from more than 1,000 cattle with histories of vaccination or infection with brucellae or both. The investigations were initiated in Pamplona, Spain, and were continued in Madison, Wis.

\section{MATERIALS AND METHODS}

Preparation of poly B. The rough strain B. melitensis B115 was grown in flasks of Trypticase soy broth (Baltimore Biological Laboratory, Cockeysville, Md.) for $48 \mathrm{~h}$ at $37^{\circ} \mathrm{C}$ on a shaker. The cells were harvested by centrifugation, washed twice with $0.15 \mathrm{M}$ $\mathrm{NaCl}$, and resuspended in deionized distilled water at a ratio of $20 \mathrm{~g}$ of packed wet cells to $100 \mathrm{ml}$ of water. An equal volume of $0.5 \mathrm{M}$ trichloroacetic acid was added. The suspension was held at $4^{\circ} \mathrm{C}$ with magnetic stirring for $18 \mathrm{~h}$ and centrifuged. The supernatant fluid was adjusted to $\mathrm{pH} 6.5$ with $\mathrm{NaOH}, 5$ volumes of cold 95\% ethanol was added, and the mixture was allowed to stand at $4^{\circ} \mathrm{C}$ overnight. The resulting white, cloudy precipitate was sedimented by centrifugation at 5,000 $\times g$ for $10 \mathrm{~min}$, dissolved in deionized distilled water, and dialyzed against deionized distilled water. Any insoluble material was removed by centrifugation, and the supernatant fluid was lyophilized. Acetone-dried cells of the same strain were used with similar results. Several preparations were made in both laboratories The yield varied from 0.4 to $0.5 \%$ on a dry weight basis.

Preparations of poly B were analyzed for total carbohydrates, protein, 2-keto-3-deoxyoctonate, and heptose by methods employed by Moreno et al. (9). They contained $80 \%$ total carbohydrates and $5 \%$ protein but did not contain detectable 2-keto-3-deoxyoctonate or heptose.

Preparation of crude S-LPS. B. melitensis smooth strain $16 \mathrm{M}$ was extracted by the hot phenolwater method modified for Brucella by M. Redfearn (Ph.D. thesis, University of Wisconsin-Madison, 1960) and described by Leong et al. (8). Both S-LPS and poly $B$ could be demonstrated in the soluble phenol fraction. 
Serological tests. The rose bengal (RB) test is a rapid serum agglutination test which was performed along with the complement fixation (CF) test. B. abortus whole cell antigens were employed with both tests, as described by Alton et al. (1).

Precipitation tests. For immunodiffusion tests by the Ouchterlony technique, gels were prepared with $1 \%$ agarose in borate buffer $(\mathrm{pH} 8.3)$ containing $10 \%$ $\mathrm{NaCl}$.

Veronal buffer ( $\mathrm{pH} 8.6$ ) and $0.8 \%$ agarose were employed in immunoelectrophoresis. At $2 \mathrm{~h}$ after the sera were added to the troughs, the slides were immersed in $10 \% \mathrm{NaCl}$ for incubation at room temperature.

RID. The gel was prepared by dissolving $1.8 \%$ agarose in $0.1 \mathrm{M}$ glycine buffer ( $\mathrm{pH} 8.6$ ) (2). Poly B was dissolved in glycine buffer to which $\mathrm{NaCl}$ had been added to a concentration of $20 \%$. Equal volumes of the gel and poly $\mathrm{B}$ solution, both at $65^{\circ} \mathrm{C}$, were mixed and dispensed on slides or plates to a depth of $1 \mathrm{~mm}$. After the gel had set, 4-mm wells were cut and removed. Test sera were added to the wells, and the slide was held in a moist chamber at room temperature. A ring of precipitation could appear within $30 \mathrm{~min}$, but final readings were taken at $3 \mathrm{~h}$.

To determine the optimum concentration of poly B for RID, slides were prepared with antigen at concentrations of from 25 to $400 \mu \mathrm{g} / \mathrm{ml}$ of gel and tested with at least 14 control sera. The concentration of antigen giving rings of precipitation with all positive control sera and no rings with negative control sera within 2 $h$ was determined, and twice that concentration was employed in the test.

Bovine sera. The RID test was performed first in Pamplona on sera obtained from the following groups of cattle: (i) group 1 (see Table 1), 78 cattle from which B. abortus ( 73 cows) or B. melitensis (5 cows) had been isolated from the milk (72 cows) or supramammary lymph nodes (6 cows); (ii) group 2, 129 cattle suspected of being infected on the basis of serological reactions in $\mathrm{RB}$ and $\mathrm{CF}$ tests; unsuccessful attempts were made to isolate brucellae from the milk of 90 of these cows; (iii) group 3, 390 cattle which did not have serological reactions and were negative on milk culture; and (iv) group 4, 90 cattle which had been vaccinated with $B$. abortus vaccine strain 19 and were believed to be free of brucellosis; the interval between vaccination and serum sampling varied from 7 days to 6 months.

Because it was difficult to verify the infection or vaccination status of cattle in Spain, where bovine brucellosis is enzootic, further evaluation of the RID test was performed in Madison by using a bank of frozen sera from herds with known histories. Many of the sera came from an infected dairy herd in Florida where adult vaccination with strain 19 had been under investigation. The results of bacteriological and serological examinations made on these animals at frequent intervals over a 13 -month period have been described (11). In addition, sera were obtained from cattle in controlled vaccination experiments performed under the auspices of the U.S. Department of Agriculture. The sera came from groups of cattle with the following histories: (i) group 1 (see Table 2), cattle in infected herds in Florida from which field strains of
B. abortus were isolated; (ii) group 2, cattle in vaccinated and infected herds in Florida and Wisconsin which were serological reactors, but for which bacteriological proof of infection was lacking; unsuccessful attempts to isolate brucella were made with half of these cows; (iii) group 3, cattle which had been vaccinated with strain 19 as adults and which became shedders of the vaccine strain; (iv) group 4, cattle which had been inoculated with a virulent strain of $B$. abortus 1.5 to 7 months previously; the inoculated strain was recovered from all; (v) group 5 , calves in a brucella-free herd which had been vaccinated with the standard dose of strain 19 when less than 6 months old and which were bled 1 to 6 months later; (vi) group 6 , cattle in an infected dairy herd in Florida which had been vaccinated subcutaneously with the standard dose of strain $19\left(9 \times 10^{10}\right.$ organisms); sera used were obtained 4 to 6 months after vaccination, at which time some were positive in $\mathrm{RB}$ and $\mathrm{CF}$ tests; on subsequent tests the titers receded, and these cows showed no clinical evidence of infection at any time; and (vii) group 7, cattle in a brucellosis-free herd which had been vaccinated subcutaneously with reduced doses of strain $19\left(5 \times 10^{9}\right.$ or $8 \times 10^{9}$ organisms $)$ and were tested 4 to 8 weeks later.

\section{RESULTS}

Two antigenic components were demonstrated in the phenol fraction of $B$. melitensis $16 \mathrm{M}$ by immunoelectrophoresis with serum from an infected cow (Fig. 1), whereas a single component was developed with poly $\mathrm{B}$. The poly $\mathrm{B}$ line was of cathodic mobility, as was that of $\mathrm{S}$ LPS, but it diffused more rapidly than the SLPS line. In immunodiffusion (Fig. 2) the fasterdiffusing component in $16 \mathrm{M}$ showed identity with the component in poly B preparations.

$\mathrm{NaCl}$ at a concentration of $10 \%$ in the gel was required for the development of the poly $\mathrm{B}$ line with most bovine sera (Fig. 3 ). When the phenol

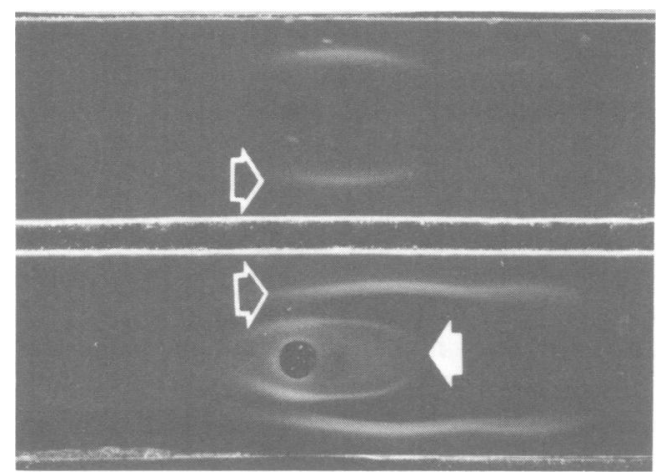

Fig. 1. Immunoelectrophoresis of preparations of poly $B$ (upper well) and $16 \mathrm{M}$ (lower well) which contains two components, reacted with serum from a cow with brucellosis. Poly B and S-LPS are indicated by open and closed arrows, respectively. Cathode is to the right. 


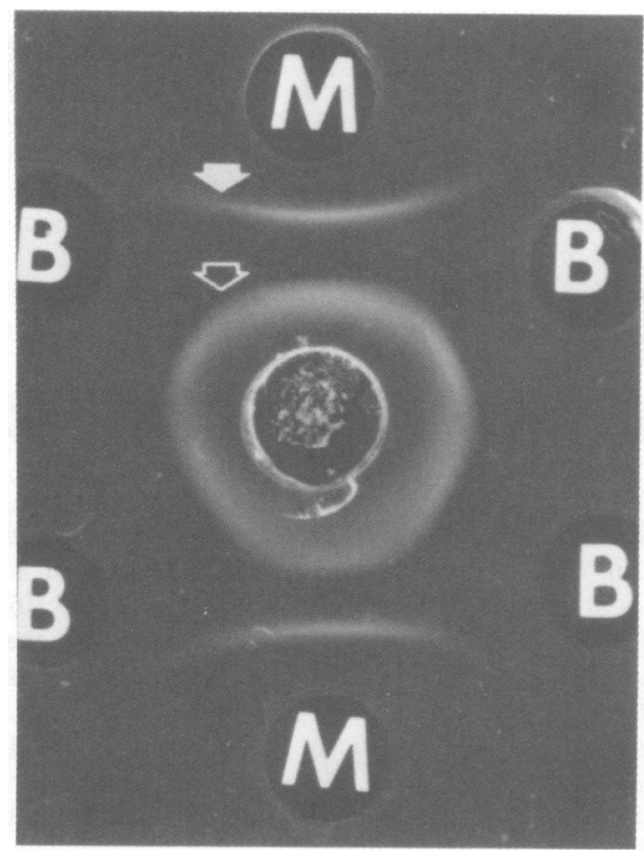

Fig. 2. Immunodiffusion of four poly $B$ preparations (B) and one $16 M(M)$ preparation reacted with serum from an infected cow (center well). The fasterdiffusing component in $16 M$ shows identity with poly $B$. Poly $B$ and S-LPS are indicated by the open and closed arrows, respectively.

fraction of $B$. melitensis $16 \mathrm{M}$ was employed in immunodiffusion with a gel containing $10 \%$ $\mathrm{NaCl}$, lines corresponding to both antigens were revealed with 73 of 78 sera from infected cattle. None of 50 sera from strain 19-vaccinated cattle developed lines corresponding to poly $\mathrm{B}$, although 16 sera demonstrated antibodies against S-LPS. Examples of these reactions are shown in Fig. 3.

These and additional sera were examined in RID plates containing poly $B$ (Table 1 ). The 73 sera from infected cattle which had developed a line corresponding to poly $\mathrm{B}$ in immunodiffusion also developed a ring of precipitation in RID. The rings appeared between $30 \mathrm{~min}$ and $2 \mathrm{~h}$. Of the sera from cattle believed to be uninfected or from cattle vaccinated with strain 19 , none was positive in the RID test. About $42 \%$ of the sera from cows suspected of having brucellosis on the basis of serological reactions developed rings in RID, although the infections were not confirmed bacteriologically.

For further evaluation of the RID test, prepared RID plates and poly $B$ antigen were sent to Madison. These plates and RID plates freshly prepared in Madison with Pamplona poly B and with Madison poly B gave identical results with
14 or more control sera. The results with stored sera (Table 2) show that vaccination with strain 19 , even when performed in adults, did not induce precipitins which reacted in RID unless the
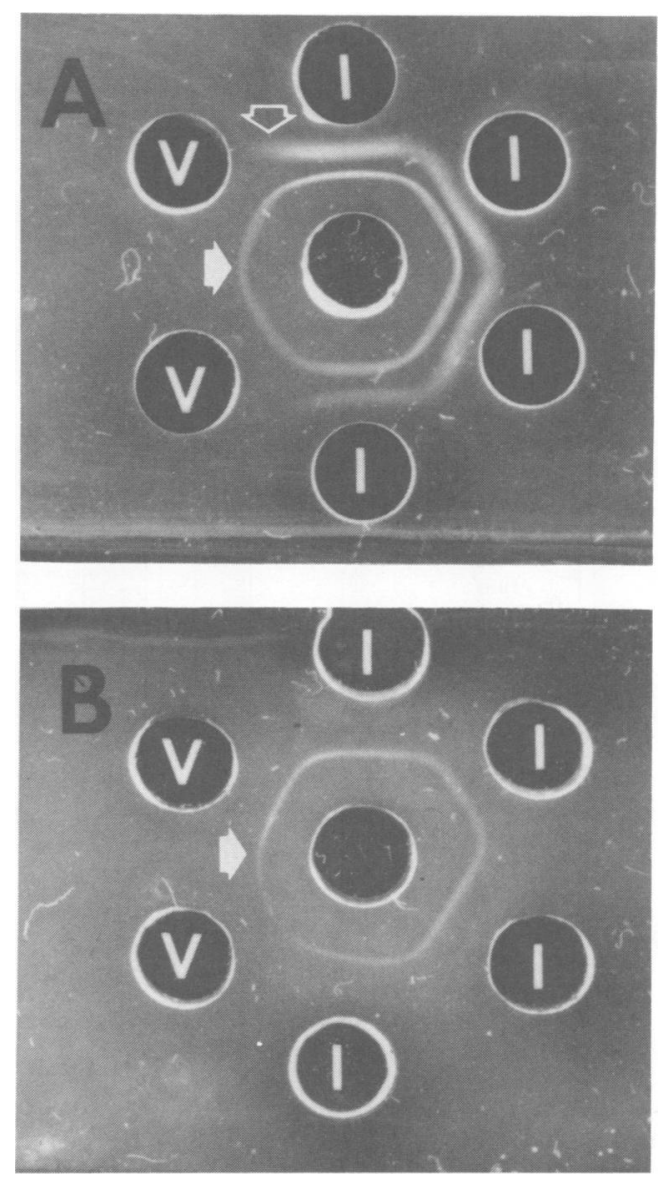

Fig. 3. Immunodiffusion of phenol fraction of $16 M$ (center well) reacted with sera from cattle which were infected (I) or vaccinated $(V)$. The gels contained $10 \%$ $\mathrm{NaCl}(\mathrm{A})$ or $0.15 \mathrm{M} \mathrm{NaCl}(\mathrm{B})$. Poly B and S.LPS are indicated by the open and closed arrows, respectively.

TABLE 1. Serological test results with bovine sera tested in Pamplona

\begin{tabular}{|c|c|c|c|c|c|c|}
\hline \multirow{2}{*}{ Group } & \multirow{2}{*}{ History } & \multirow{2}{*}{$\begin{array}{l}\text { No. } \\
\text { tested }\end{array}$} & \multicolumn{3}{|c|}{$\begin{array}{l}\text { No. positive } \\
\text { by: }\end{array}$} & \multirow{2}{*}{$\begin{array}{c}\% \text { Posi- } \\
\text { tive in } \\
\text { RID } \\
\text { test }\end{array}$} \\
\hline & & & RB & CF & RID & \\
\hline 1 & $\begin{array}{l}\text { Bacteriologically } \\
\text { proved infec- } \\
\text { tions }\end{array}$ & 78 & 78 & 78 & 73 & 93.5 \\
\hline 2 & $\begin{array}{l}\text { Suspected infec- } \\
\text { tions }\end{array}$ & 129 & 129 & 129 & 54 & 41.8 \\
\hline 3 & Negative & 390 & 0 & 0 & 0 & 0 \\
\hline 4 & Vaccinated & 90 & 61 & $\mathrm{NT}^{a}$ & 0 & 0 \\
\hline
\end{tabular}

" NT, Not tested. 
TABLE 2. Serological test results with bovine sera tested in Madison

\begin{tabular}{|c|c|c|c|c|c|c|}
\hline \multirow{2}{*}{ Group } & \multirow{2}{*}{ History } & \multirow{2}{*}{$\begin{array}{l}\text { No. } \\
\text { tested }\end{array}$} & \multicolumn{3}{|c|}{$\begin{array}{l}\text { No. positive } \\
\text { by: }\end{array}$} & \multirow{2}{*}{$\begin{array}{c}\% \text { pos- } \\
\text { itive in } \\
\text { RID } \\
\text { test }\end{array}$} \\
\hline & & & $\mathrm{RB}$ & $\mathrm{CF}$ & RID & \\
\hline 1 & Field infections ${ }^{a}$ & 70 & 70 & 70 & 54 & 77.1 \\
\hline 2 & $\begin{array}{l}\text { Suspected infec- } \\
\text { tions }\end{array}$ & 46 & 46 & 46 & 36 & 78.3 \\
\hline 3 & $\begin{array}{l}\text { Vaccine strain in- } \\
\text { fections }{ }^{a}\end{array}$ & 12 & 12 & 12 & 9 & 72.7 \\
\hline 4 & $\begin{array}{l}\text { Exprimental infec- } \\
\text { tions }\end{array}$ & 35 & 35 & 35 & 31 & 88.6 \\
\hline \multirow[t]{4}{*}{5} & $\begin{array}{l}\text { Calves vaccinated } \\
\text { with standard } \\
\text { dose and } \\
\text { tested: }\end{array}$ & & & & & \\
\hline & $\begin{array}{l}1 \text { to } 2 \text { months } \\
\text { after vaccina- } \\
\text { tion }\end{array}$ & 20 & 9 & 9 & 0 & 0 \\
\hline & $\begin{array}{l}3 \text { to } 4 \text { months } \\
\text { after vaccina- } \\
\text { tion }\end{array}$ & 19 & 2 & 1 & 0 & 0 \\
\hline & $\begin{array}{l}5 \text { to } 6 \text { months } \\
\text { after vaccina- } \\
\text { tion }\end{array}$ & 24 & 0 & 0 & 0 & 0 \\
\hline \multirow[t]{3}{*}{6} & $\begin{array}{l}\text { Adults vaccinated } \\
\text { with standard } \\
\text { dose and } \\
\text { tested: }\end{array}$ & & & & & \\
\hline & $\begin{array}{c}4 \text { months after } \\
\text { vaccination }\end{array}$ & 83 & 60 & 28 & 0 & 0 \\
\hline & $\begin{array}{c}6 \text { months after } \\
\text { vaccination }\end{array}$ & 17 & 16 & 6 & 0 & 0 \\
\hline 7 & $\begin{array}{l}\text { Adults vaccinated } \\
\text { with reduced } \\
\text { dose and tested } \\
1 \text { to } 2 \text { months } \\
\text { after vaccina- } \\
\text { tion }\end{array}$ & 47 & 44 & 24 & 0 & 0 \\
\hline
\end{tabular}

${ }^{a}$ Bacteriologically proved infections.

vaccine strain became established in the cow and was shed in the milk. About $80 \%$ of the sera from 117 bacteriologically proved infections (groups 1, 3, and 4) were positive in RID.

\section{DISCUSSION}

It had been reported previously (5) that partially purified bovine immunoglobulin G1 precipitates Brucella antigens more rapidly in gels containing an increased concentration of $\mathrm{NaCl}$ than in isotonic gels. We observed that $10 \%$ $\mathrm{NaCl}$ in the gel was required for the precipitation of poly $\mathrm{B}$ by most bovine sera. We do not know at this time whether this is due to the relatively high proportion of immunoglobulin G1 with anti-poly B specificity or simply to enhanced precipitation of soluble antigen-antibody complexes in the presence of high concentrations of salt.

Antibody to poly B was not observed in sera of rabbits immunized with killed antigens known to contain poly $\mathrm{B}$, although sera of rabbits infected with smooth virulent brucellae contained precipitins to poly B (4). B. abortus strain 19 cells contain S-LPS and poly $B$, but cattle vaccinated with smooth living strain 19 do not produce antibodies against poly B detected by RID unless strain 19 becomes established as a bacteriologically demonstrable infection. This rarely occurs if vaccination takes place before sexual maturity but is more frequent when lactating or pregnant cattle are vaccinated (12).

As S-LPS is an immunodominant antigen, antibody to S-LPS is the first to appear after vaccination or infection with $B$. abortus. It seems likely that further stimulation is required for the production of antibody to poly $\mathrm{B}$, and this may be provided by multiplication of the organism such as would occur during infection. Thus, the presence of antibody to poly B may correlate more closely with active infection than does the presence of antibody to S-LPS. Poly B lacks 2-keto-3-deoxyoctonate, one of the specific markers of LPS, but the exact nature and location of poly B in the Brucella cell remains to be determined.

There is need for a rapid, simple, specific test for brucellosis (12). The RB test (or card test as it is designated in the United States) is a rapid and simple agglutination test that can be used in the field as well as in laboratories with limited facilities. However, in animals that have been vaccinated with strain 19 , it gives many falsepositive reactions (12). The CF test is more specific than the RB test, but it gives some falsepositive reactions after adult vaccination $(10$, 11). The CF test is technically difficult to perform on the large scale required.

When adult vaccination is carried out in an attempt to stop the spread of infection in a herd, it is essential to detect and remove actively infected animals as soon as possible. In this situation, the use of the RID test to confirm the results of the RB test, even if it did not detect all of the infected animals, would be preferable to waiting until $\mathrm{RB}$ reactions due to vaccination had receded in the herd.

It is suggested that, in routine serological diagnosis of bovine brucellosis, the RID test with poly $B$ could be employed as an initial confirmatory test on the RB-positive sera and that the results could be available the same day. If a serum were positive, the corresponding animal could be considered infected and separated from the negative animals. If the RID test were negative, the serum should be tested by CF or other confirmatory tests, as the RID test cannot be considered a substitute confirmatory test at this time. 


\section{ACKNOWLEDGMENTS}

We thank Gordon Janney and Paul Nicoletti for the data and sera from the infected herds in Wisconsin and Florida, respectively, and the National Animal Disease Center, Ames, Iowa, for data and sera from the experimentally infected cattle.

The work in Madison was supported by the College of Agriculture and Life Sciences, by a grant from the Dairy Research Foundation, and by cooperative agreements with the Animal and Plant Health Inspection Service and the Science and Education Administration, U. S. Department of Agriculture.

\section{LTERATURE CITED}

1. Alton, G. G., L. M. Jones, and D. E. Pietz. 1975. Laboratory techniques in brucellosis. World Health Organization Monograph Series no. 55. World Health Organization, Geneva.

2. Chase, M. W. 1968. Appendix II. Buffers, p. 396. In C. A. Williams and M. W. Chase (ed.), Methods in immunology and immunochemistry, vol. 2. Academic Press Inc., New York.

3. Diaz, R., and I. Dorronsoro. 1971. Contribution to the serological diagnosis of brucellosis and yersiniosis. I. Use of the gel precipitation reaction. Rev. Clin. Esp. 121:367-372.

4. Diaz, R., L. M. Jones, D. Leong, and J. B. Wilson. 1968. Surface antigens of smooth brucellae. J. Bacteriol. 96:893-901.

5. Diaz, R., and D. Levieux. 1972. Respective role in the serology of bovine brucellosis of antigens and of immunoglobulins $G_{1}$ and $G_{2}$ in the tests of agglutination, of Coombs and of Rose Bengal and in the zone phenomenon. C. R. Acad. Sci. 274:1503-1596.

6. Diaz, R., E. Maravi-Poma, and A. Rivero. 1976. Comparison of counter-immunoelectrophoresis with other serological tests in the diagnosis of human brucellosis. Bull. W.H.O. 53:417-424.

7. Iannelli, D., R. Diaz, and T. M. Bettini. 1976. Identification of Brucella abortus antibodies in cattle serum by single radial diffusion. J. Clin. Microbiol. 3:203-205.

8. Leong, D., R. Diaz, K. Milner, J. Rudbach, and J. B. Wilson. 1970. Some structural and biological properties of Brucella endotoxin. Infect. Immun. 1:174-182.

9. Moreno, E., M. W. Pitt, L. M. Jones, G. S. Schurig, and D. T. Berman. 1979. Purification and characterization of smooth and rough lipopolysaccharides from Brucella abortus. J. Bacteriol. 138:361-370.

10. Nicoletti, P., L. M. Jones, and D. T. Berman. 1978 Adult vaccination with standard and reduced doses of Brucella abortus strain 19 vaccine in a dairy herd infected with brucellosis. J. Am. Vet. Med. Assoc. 173: 1445-1449.

11. Nicoletti, P., L. M. Jones, and D. T. Berman. 1978. Comparison of the subcutaneous and conjunctival route of vaccination with Brucella abortus strain 19 vaccine in adult cattle. J. Am. Vet. Med. Assoc. 173:1450-1456.

12. World Health Organization. 1971. Fifth report of the Joint FAO/WHO Expert Committee on Brucellosis. WHO Technical Report Series no. 464. World Health Organization, Geneva. 